\title{
ENANOS Y GIGANTES EN MITOLOGÍAS INDÍGENAS Y LA ARQUEOLOGÍA DE COLOMBIA
}

Hugo A. Sotomayor Tribín MD*

\section{Resumen}

Se presentan las mitologías de siete pueblos indígenas colombianos, Ika, Bari, Yukpa, Desana, Páez, Embera y Sicuani, y se relacionan con las pequeñas estatuillas cerámicas con representación de diferentes tipos de enanismo que dejó la llamada cultura Tumaco-La Tolita, que floreció entre los años 400 a.C. y 400 d.C. Se concluye que estas figurillas fueron ofrendas dejadas a espíritus protectores de los animales en particular y de la naturaleza en general, similares a las diversas ofrendas que se le hacen a los pequeños seres que tienen esas funciones en las mitologías de los pueblos arriba referidos.

Los gigantes, el opuesto de los enanos, son concebidos en las mitologías indígenas como seres que pueden crear riesgos en la relación de equilibrio con la madre tierra. Por ser seres peligrosos, negativos, su representación en el arte precolombino es casi inexistente.

Palabras clave: mitología, sueños, conciencia, enanos, gigantes, estatuillas, naturaleza, fertilidad.

\section{Introducción}

Todas las sociedades antiguas y entre ellas las indígenas amerindias le dieron y le dan un valor muy especial a los estados de conciencia diferentes a los de la propia vigilia. En ellas los sueños y los estados de conciencia asociados con diferentes privaciones y el uso de sustancias con poder sobre la mente han sido usados para conocer, entender e interpretar los mundos circundante y propio. Ellas han usado esos estados modificados de conciencia para potenciar los registros que sobre el mundo circundante hacen sus sentidos.

El arte y las mitologías, como procesos mentales, tienen en común trabajar con imágenes que buscan explotar los contrastes y las similitudes de las cosas.

Fecha recibido: febrero 7 de 2007-Fecha aceptado: febrero 26 de 2007

* Coordinador del Grupo de Antropología Médica y de la Salud de la Fundación Universitaria de Ciencias de la Salud.
Las mitologías se han construido sobre el conjunto de imágenes y símbolos nacidos en esos momentos especiales de la conciencia; ellas no han sido, en su núcleo principal, el producto sólo de elucubraciones nacidas en perfectos estados de vigilia y de la lógica.

La interpretación de los sueños con ricas imágenes visuales, los sueños nacidos en lo que hoy se sabe que es la fase REM ( por sus siglas en ingles de Rapid Eye Movement ) por ser los mejor estructurados y los que se recuerdan y de los trances inducidos, han sido la cantera de las mitologías.

Las imágenes y los recuerdos de los procesos oníricos peculiares y de los trances, asociados, los primeros, a lo que se ha llamado el inconsciente colectivo o los arquetipos, al ser sometidos a socializaciones e interpretaciones culturales por chamanes y sacerdotes, dan lugar a los cuerpos de las cosmovisiones y a las mitologías en las diferentes sociedades. 
Esas representaciones en las mitologías y el arte de esas sociedades premodernas obedecieron, con seguridad, a lo que se ha llamado el predominio del pensamiento analógico, comparativo y de contraste binario tan asociados al hemisferio cerebral derecho.

En ese mundo de analogías todas las sociedades antiguas y aún la moderna echan mano de las polaridades para comprender el mundo. Son características los opuestos de día-noche, sol-luna, derecha-izquierda, arriba-abajo, adelante-atrás, frío-calor, macho-hembra, esperma-sangre, etc, así como las de bello-feo, habitual-infrecuente, enano y gigantes, bueno-malo, vigilia-sueño.

Las personas con rasgos físicos opuestos a lo que en las sociedades se considera lo habitual siempre han llamado la atención de una u otra forma. Ellas han sido representadas en mitologías y en las obras artísticas de las sociedades premodernos y son objeto de los estudios científicos en las sociedades modernas.

El registro de los testimonios de la cultura material de las sociedades antiguas, objeto de la disciplina arqueológica, muestra con mucha frecuencia obras de gran belleza formal que representan personas y o seres con características físicas diferentes a las normas de las sociedades en las que aquellas se crearon. Así, aparecen enanos, gigantes, andróginos, siameses, hirsutos, amputados, deformes etc.

\section{Objetivo}

Como es sabido que los pueblos indígenas colombianos no dejaron testimonios escritos sobre sus mitologías, es claro que su estudio no se puede hacer sino partiendo del presupuesto de lo que de ellos se puede inferir de los mitos de los supervivientes pueblos indígenas actuales. Las mitologías de los indígenas actuales, soportada en los arquetipos y en concepción del tiempo circular, dan claras luces sobre la de los pueblos del pasado. El estudio de las mitologías de los pueblos antiguos sirve para entender e interpretar el registro plástico que ellos dejaron sobre esos seres tan peculiares físicamente. La mitopoética sirve a los estudios arqueológicos (Llano, 1995).

Este trabajo, con base en lo anterior, busca establecer un vínculo entre las mitologías de los pueblos indígenas actuales y los registros arqueológicos que sobre enanos y gigantes estén referidos y estudiados en Colombia.

\section{Presentación de la situación}

El concepto de enano y gigante cambia en cada sociedad según la estatura promedio de cada una de ellas y el momento histórico. Hoy se acepta que en general hay dos grandes clases de enanismo. La primera es la dada por personas adultas de estatura menor de 143-140 cm sin alteración de las proporciones corporales; y la segunda con las mismas tallas pero con alteración de las proporciones corporales. En el primer grupo se consideran las afecciones de origen endocrinológico y nutricional entre otras, y en las segundad, en general, las de origen óseo.

Los pueblos amerindios variaron en su estatura. Entre los grupos de mayor promedio están los Ona de la Tierra del Fuego, con su media de $183 \mathrm{~cm}$. Entre los más bajos se cuentan algunos grupos Yukpa o Yukos de la Serranía de Perijá entre Colombia y Venezuela, con su media de $158 \mathrm{~cm}$ (Coon, 1984).

Hoy es claro para todas las disciplinas sociales aceptar que de una u otra forma las necesidades de orden material que tienen las sociedades influyen decisivamente en el mundo de las ideas. La necesidad de mantener el equilibrio entre la capacidad de carga de los modos de producción y la población, influye en la construcción de las cosmovisiones.

Para los pueblos indígenas colombianos del pasado y del presente el éxito de las sociedades humanas consistió y consiste en el equilibrio entre lo que se toma y lo que se le da a la madre tierra. Su preocupación era y es la preservación del equilibrio 
entre la sociedad humana y el resto de la naturaleza, en virtud a su idea de que el hombre es una de sus partes y no su dueño.

Las sociedades indígenas que habitaron lo que hoy es Colombia, al ser sociedades de cazadores-recolectores y de agricultores, estuvieron signadas por las constantes presiones sobre el delicado equilibrio entre los recursos y la población. Cualquier carga extrema, el exceso de habitantes o cualquier habitante mayor o persona muy débil que se convirtiera en un peso excesivo y prolongado para los demás, en virtud a su incapacidad para autosostenerse, era visto por el conjunto de las familias y de la sociedad como un riesgo para todo el conjunto social.

En esta perspectiva es que los recién nacidos con deformaciones y debilitados por enfermedades -entre ellos algunos casos de enanismo congénito- fueron abandonados o eliminados a través de las prácticas del infanticidio activo o pasivo. Pero esto con seguridad no lo hicieron con los niños cuyas características propias de los diferentes tipos de enanismo se manifestaban meses después de haber nacido. A estos últimos niños tras su aceptación social al darles un nombre, se les asignaban ciertas faenas y se les miraba a través de sus cosmovisiones.

Entre los Yukpa o Yukos se han descrito subgrupos de menos estatura y con una deformidad afectados por una displasia esquelética espondilo epifisio-metafisiaria (Arias, Mota, Pinto, 1976) y con alteraciones de las hormonas somastotina y somatomedina (Arias, 1976). Al manifestarse ambas alteraciones, principalmente la osteocondrodistrofia, después de los cuatro años de vida, los niños que las presentan se libraron de las habituales prácticas de infanticidio.

La sobrevida y ajuste social de ciertos enanos a las sociedades precolombinas es muy clara en las notas que sobre ellos dejaron los cronistas en Perú y México:
Hernán Cortés escribió sobre estas personas que encontró en la vivienda de Moctezuma en la capital azteca, Tenochtitlán: "Tenía en esta casa un cuarto en que tenía hombres y mujeres y niños blancos de su nacimiento en el rostro y cuerpo y cabello y cejas y pestañas... Tenía otra casa donde tenía muchos hombres y mujeres monstruos, en que había enanos, corcovados, y otros con otras deformidades, y cada una manera de monstruos, en su cuarto por sí, e también había para éstos personas dedicadas para tener cargo dellos" (Cortés, 1985).

Felipe Guaman Poma de Ayala escribió sobre la situación de las personas con defectos físicos, entre ellos los enanos, en el Perú: "En esta calle del quarto de los enfermos y liciados, cojos y mancos y tullidos, upa, mudo; nausa, ciego; uncoc, enfermo; uinay uncoc, tullido; maquin paquisca, manco; hanco, coxo.Estos servían de pasatiempo, hablar y cjocarrear, como son enanos, tinre, uayaca; cumo, corcobado; chicta cinca (naríz partida). Cada uno de los que podían trabajar y ayudar, los que tenían ojos servían de mirar, los que tenían pies andaban, los que tenían manos texían y servían de despenseros y quipo camayos, mayordomos. Éstos cada uno les casaban con su igual para multiplicar y servían en todo lo que pudían ....Le casaban al ciego con otra ciega, al cojo con otra coja, al mudo con otra muda, el enano con enana, al corcobado con corcobada, el naríz hendido con otra de naríz hendida, para el multiplico del mundo....Y éstos tenían sus sementeras, casas, eredades y ayuda de su servicio y ancí no avía menester hospital ni limosna con esta horden santa y pulicía deste rreyno..." (Poma de Ayala, 1987).

\section{Material}

El registro arqueológico de enanos en las sociedades indígenas precolombinas colombianas es claro en la cultura Tumaco-La Tolita. Las mitologías analizadas corresponden a las sociedades de los indígenas Bari y Yukpa de la Serranía de Perijá, los Desana de Vaupés, los Páez de Tierradentro (Cauca), los Ika o Arhuacos de la Sierra 
Nevada de Santa Marta, los Embera de Chocó y Risaralda y los Sicuani de Casanare y Vichada.

Para los indígenas Bari de lengua chibcha, de la Sierra de Perija ubicados en la frontera norte de Colombia con el nor-occidente de Venezuela, y cuyo número en Colombia se ha estimado alrededor de 500 personas, el plano subterráneo el Baira biashá barun de ellos, gira en torno al personaje llamado Sibatyi. Igual concepción tienen sus vecinos de lengua karib, los Yukpa, ubicados al sur de esta Sierra, y cuyo número en Colombia parece ascender a 2.200; al personaje en cuestión lo llaman Pïpïntu.

Este personaje, Sibatyi o Pïpïntu que figura en sus mitologías con la cara pintada de rayas de colores rojos, negros y blanco tiene la capacidad de comunicarse con los muertos viajando a través de las cuevas $\tan$ frecuentes en la Sierra de Perijá. A Sibatyi se le imagina con los pies torcidos, descalzo y con solo un guayuco y a Pïpïntu se le imagina como un enano, descalzo y con guayuco (Vitoria, 2002).

Entre los Páez de Tierradentro, en la cordillera Central en el departamento del Cauca, cuyo número se calcula entre 90.000 y 100.000 personas, cuya lengua nasayuwe se aceptó hasta hace poco y sin lugar a dudas de la familia chibcha, hoy se considera como una lengua de filiación por precisar, existe la idea que el personaje llamado por ellos Cllumb, es un enano con los pies torcidos que tiene como una de sus funciones vigilar los lugares sagrados como las lagunas, cuevas, peñascos, corrientes de agua y algunos cerros de su territorio.

Los Páez relatan que este personaje, conocido en castellano como El Duende, castiga a las personas que no lo agasajan o irrespetan los lugares sagrados, arrojándoles piedras y palos, escondiéndoles los niños y objetos u ocasionándoles fuertes dolores, fiebres, altas y tembladera.

Al Cllumb o Duende hay que darle como ofrenda parte de las cosechas y dejarle como ofrenda en las visitas a los lugares sagrados coca, tabaco y el aguardiente de anís conocido en Tierradentro como chancuco.

El médico tradicional Páez, el the'wala, es la persona que debe prevenir la ira del Cllumb o Duende, velando por que las personas tenga cuidado con la naturaleza, en especial con los lugares sagrados, no violen las normas sociales que ocasionan la retaliación de aquel, y tratando las dolencias ocasionadas por El Duende.

En la cosmología de los Páez, al igual que entre la de muchos pueblos del macizo colombiano y los aymaras de los andes centrales, se cree que en el mundo subterráneo hay un gran poder genésico. Entre los Páez se habla también que en el mundo de abajo, el mundo que ellos creen que está habitado por los que fueron sus enemigos ancestrales, los pijaos, la gente pequeñita sin rabitos, los nasa lets' y kwe (Puerta, 2001).

Los Desana, cuya lengua pertenece a la familia tucano, y que hasta principios del siglo XXI su número se calculaba entre 800 y 2.000 hablantes, y que se ubican en las inmediaciones del río Papurí y en los caños Abiyú, Maca y Viña y algunos en las costas del río Vaupés, tienen en su conjunto de concepciones sobre el mundo, su cosmología, la certeza que el personaje llamado por ellos Wai-maxsë o dueño de los animales, es un enano todo pintado de rojo y que porta un bastón rojo, que habita los lugares considerados no solo por los Desana, sino por todos los pueblos amazónicos, casa de los animales: los cerros, los pozos y los raudales de los ríos.

Wai-maxsë, para los Desana es el encargado de vigilar que los cazadores y pescadores no se apropien en exceso y pongan en peligro de extinción a los animales. Él castiga con enfermedades y desgracias a las personas que cometen esos abusos contra sus protegidos animales.

Los Desana tienen también en su cosmovisión otro ser enano que porta un bastón y un cilindro de cuarzo, éste es Toré-wásti. El vive en la selva y domina hábil arquero de flechas. 
La tradición amazónica en general y Desana en particular asocia a Wai-maxsë con la picardía sexual, por sus hábitos de espiar a las parejas y celar a las mujeres. El carácter fálico de los enanos Wai-maxsë y Toréwásti se determina por los bastones que portan.

Sólo los payes amazónicos y las personas purificadas por ellos y en estados de trance por el consumo del polvo de vixó, la ingestión de yajé, pueden hablar con el enano Wai-maxsë sin riesgo de ser maltratados. En estas visitas que se hacen a los lugares sagrados se dejan ofrendas y pueden estar adornados por petroglifos (en los cerros) o petroglifos (en los raudales) (Reichel-Dolmatoff, 1986).

En la mitología de los indígenas amazónicos se habla de Boráro, como de un gigante velludo con un gran pene y con los pies -trozos cilíndricos de madera-torcidos hacia atrás, encargado de destruir la sexualidad, de confundir y atacar a los cazadores, ayudado por los cerdos salvajes o pecaríes. Él mata a los hombres con su orina venenosa o abrazándolos hasta ablandarlos pero sin romperles los huesos. Boráro y Wai-maxsë son los aspectos negativo y positivo, lo prohibido y lo permitido del concepto de la fertilidad (Reichel-Dolmatoff, 1986).

Los Ika o Arhuaco de la familia lingüística chibcha, habitantes de la vertiente sur oriental de la Sierra Nevada de Santa Marta y cuyo número asciende a 10.000 personas también tienen en su cosmología una idea sobre los enanos. Ellos los llaman en su lengua Ikwu-ney.

Para los Arhuacos las personas muy pequeñas son la esencia, el espíritu de los seres humanos; ellos cuidan los lugares especiales de su mundo como son las lagunas, los cerros, los mares; son deidades protectoras de los humanos. A ellos se les asemeja a las hormigas más pequeñas por su capacidad de asociación y de enfrentar en comunidad los peligros. Ellos en palabras de Arwa Viku, el mamo arhuaco informante de esta versión, tienen su ave, su "gallina" propia, el colibrí más pequeño que existe en la Sierra
Nevada de Santa Marta, que por sus habilidades para hacer sus nidos de todos los "pelos" de la naturaleza es capaz de construir un nido de apariencia grande, pero con una apertura tan estrecha que solo cabe el. Cuando estos colibríes son invocados por los indígenas ika, ellos están convocando también a los enanos, a los protectores de los humanos.

Los enanos portan un bastón de color negro o rojo, del corazón de un árbol, que cargado de poder les sirve para luchar contra los gigantes, expresión de la voracidad y de la desmesura, llamados ikwu-varing.

Los seres pequeños al consumir menos, al ocupar menos espacio mantienen una relación de equilibrio con la madre tierra y sus recursos; los gigantes no, ellos no son solo peligrosos para la humanidad sino para todo el equilibro de la vida, de la madre tierra. Los gigantes, ikwu-varing, en razón a su tamaño y competencia por los recursos y el espacio no pueden vivir en comunidad.

En la lucha entre los enanos y los gigantes han primado los primeros. En la Sierra de Santa Marta en el camino de Nabusímaque a La Caja se ve una gran laja en donde, según la mitología Ika, en su lucha contra los enanos un gigante resbaló y pereció. Esta lucha a favor de los enanos sobre los gigantes también la expresa la mitología de los arhuacos en la victoria de un pequeño colibrí sobre un pájaro grande, al atravesarle su gran cuerpo con el suyo después de caer con su pico en él. Para el pensamiento mamo de los Ika el gigantismo en tamaño físico, en ambiciones, en desmesura rompe el equilibrio con la madre tierra. (Arwu Viku, 2007).

Aunque entre los indígenas Embera no hay descripciones claras sobre enanos, existe entre ellos la idea de los seres protectores o dueños de los animales. Estos que viven en las oquedades del mundo subterráneo, de los ríos y las selvas, son entendidos como la esencia, es decir como una parte pequeña pero concentrada de los animales que ellos tutelan. Ellos son concebidos como "madres" del agua" o de los "peces"; 
como "señor de los animales selváticos". El "jai" es la esencia, la energía real y material de las cosas, de todo lo existente. Para los indígenas Embera los jais de animales selváticos resultan de la transformación del "alma" de los muertos. (Vasco, 1985). Se calcula que el total de los Embera hablantes es de 21.500.

En la mitología Sicuani, según el miembro de esa comunidad Agustín Rodríguez -asesor del resguardo indígena de Caño Mochuelo, en el extremo oriental del departamento de Casanare y presidente de la Asociación de Pueblos indígenas de la Orinoquia colombiana, Asopio-los seres pequeños o enanos, invisibles normalmente, son seres subterráneos, del mundo de abajo, ainawi, que encargados de velar por la energía a que todo ser viviente tiene derecho, se comunican con las divinidades para lograr el tan preciado equilibro con la naturaleza. Estos seres que no son invocados, sino que se presentan a personas especiales para anunciar noticias de gran significación para los pueblos, como las catástrofes naturales y o las epidemias, son imaginados como dotados de gran musculatura en las extremidades, con ojos azules $\mathrm{y}$ de un color rojizo natural portando un aba. Este aba es un objeto circular con muchas figuras en su interior que juegan un papel importante para saber si hay que atrapar energías negativas o positivas (Rodríguez, 2007). Se calcula que el total de los Sicuani hablantes es de 15.000.

En los restos arqueológicos de la cultura colombo-ecuatoriana Tumaco-La Tolita, que floreció entre el 400 a.C. hasta el 400-500 d.C. en la costa pacífica entre las actuales poblaciones ecuatoriana de Esmeralda y colombiana de Buenaventura, se registran muchos ejemplos en su producción cerámica de casos de diferentes tipos de enanismo, entre los que se distinguen la acondroplasia, la hipocondroplasia, la pseudoacondroplasia, la acromesomelia, la displasia espóndilo-epifisiaria tarda, el síndrome de Morquio u otro tipo de mucopolisacaridosis o mucolipidosis, y la displasia torácica asfixiante de Jeune (Figuras 1,2,3,4,5,6 y 7).
Contrasta con la frecuente representación en la cerámica de enanos, la escasez de la de los gigantes. El autor de estas líneas sólo conoce una cerámica que por características faciales podría corresponder a un caso de acromegalia (Sotomayor, 1992, 1999).

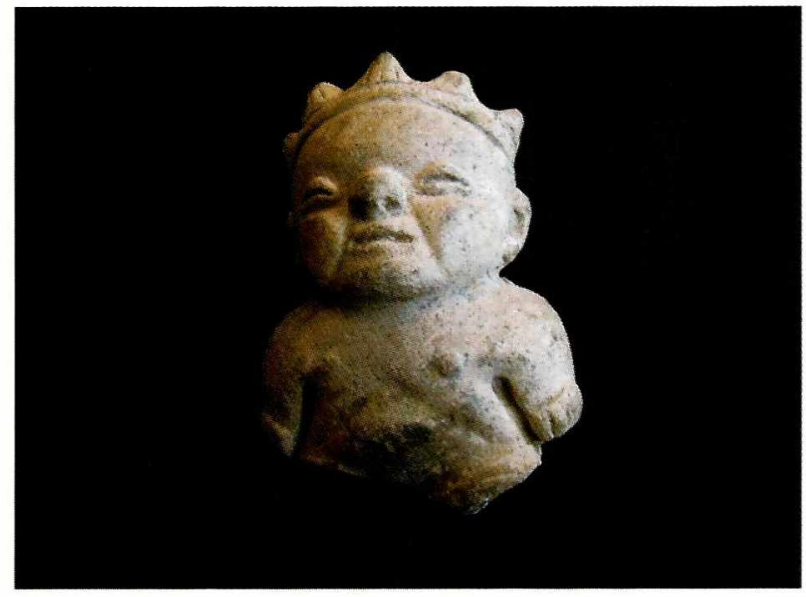

Figura I. Personaje masculino con un cuadro de acondroplasia y un tocado tipo corona de cinco puntas.

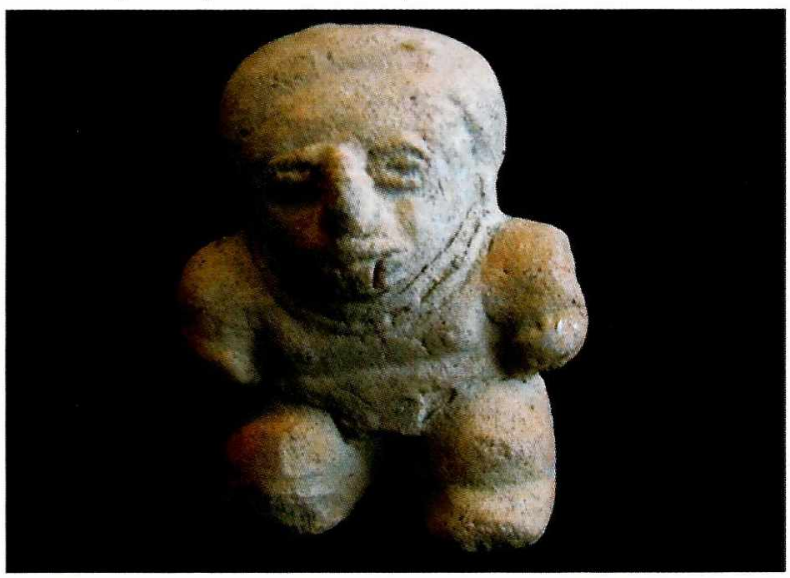

Figura 2. Personaje masculino con probable hipocondroplasia.

Figura 3. Personaje masculino con probable pseudoacondroplasia.

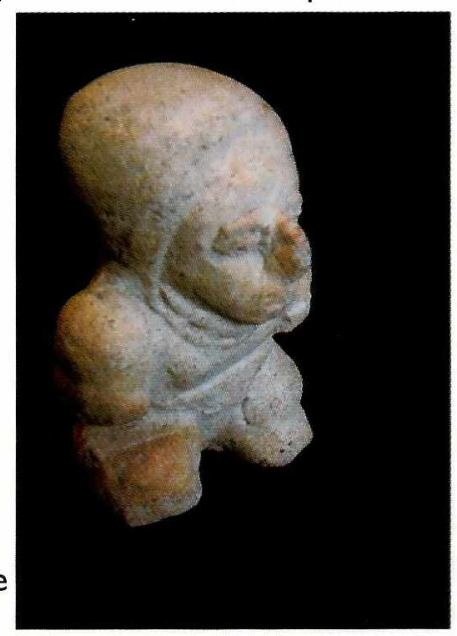




\section{Discusión}

Todo el anterior recorrido alrededor de las mitologías de siete etnias actuales nos debe servir para entender que las representaciones de enanos que se encuentran en la producción cerámica de la cultura Tumaco-La Tolita, con seguridad fueron confeccionadas como ofrendas o exvotos a los seres o personajes depositarios del cuidado de los lugares sagrados y de esta forma aplacar sus iras y retaliaciones (Sotomayor, 1990, 1999).

Con seguridad la representación tan realista de muchos personajes masculinos con varios tipos de enanismo en la cultura Tumaco-La Tolita fue fiel reflejo de la ocurrencia en esa sociedad de esas osteocondrodisplasias, todas ellas no fácilmente diagnosticables al comienzo de la vida.

Aunque bastante improbable, es posible que en la cultura Tumaco-La Tolita se hubiera presentado una situación similar con respecto a esas patologías a la que se da en el presente en un subgrupo de la población Yukpa.

Estas figurillas cerámicas de enanos debieron ser objetos revestidos de gran poder, similar al que tienen los pequeños marunsamas que cargan en sus mochilas los Ika en general y sus mamos en particular. Este aserto es palmario en la cerámica que representa la acondroplasia que, al igual que los personajes importantes de las comunidades indígenas, lleva un tocado hecho de una corona, en este caso de cinco puntas.

Como se sabe que, en conjunto, en las sociedades modernas, las más de 100 entidades clínicas que conforman el grupo variopinto de las osteocondrodisplasias, tiene una incidencia de 1 por 10.000 nacimientos, se asume que la presencia de éstas entidades en las pequeñas sociedades indígenas precolombinas debió obedecer a focos o agrupamientos de ellas al igual que ocurre con la población Yukpa actual, en razón a diferentes prácticas sociales que afectaban la deriva genética. La escasa representación de

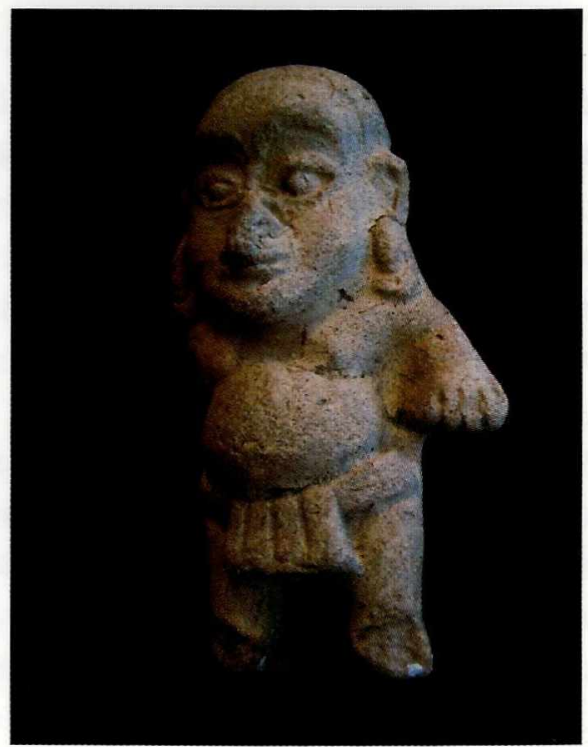

Figura 4. Personaje masculino con probable acromesomelia.

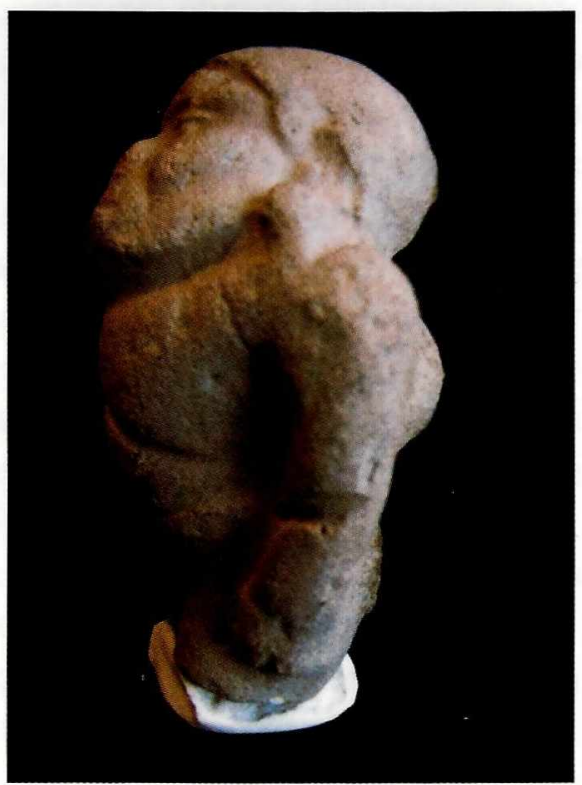

Figura 5. Personaje masculino con giba parte de una probable displasia espondiloepifisiaria tarda.

gigantismo obedeció con seguridad a su asociación con el peligro de la sobre-explotación de la madre tierra y por la menor frecuencia de los casos, por ejemplo de la acromegalia en la población- menos de $0,5 \times 10.000$ habitantes- y su más frecuente aparición en las décadas cuarta o quinta de la vida, a las que no llegaban la mayoría de los indígenas ni la población mundial antes del siglo XX.

En la mitología germánica, escandinava y de otros lugares del mundo también existen múltiples refe- 


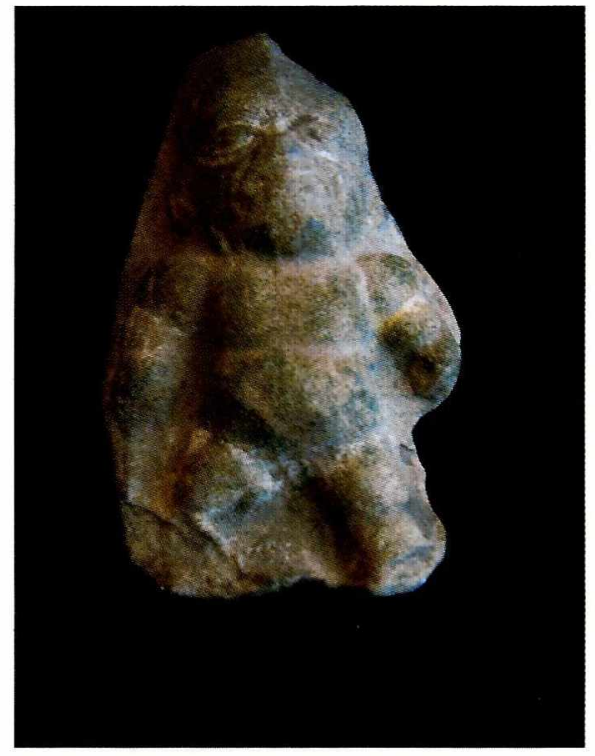

Figura 6. Personaje masculino con rostro abotagado por probable mucopolisacaridosis (¿Morquio?) o mucolipidosis.

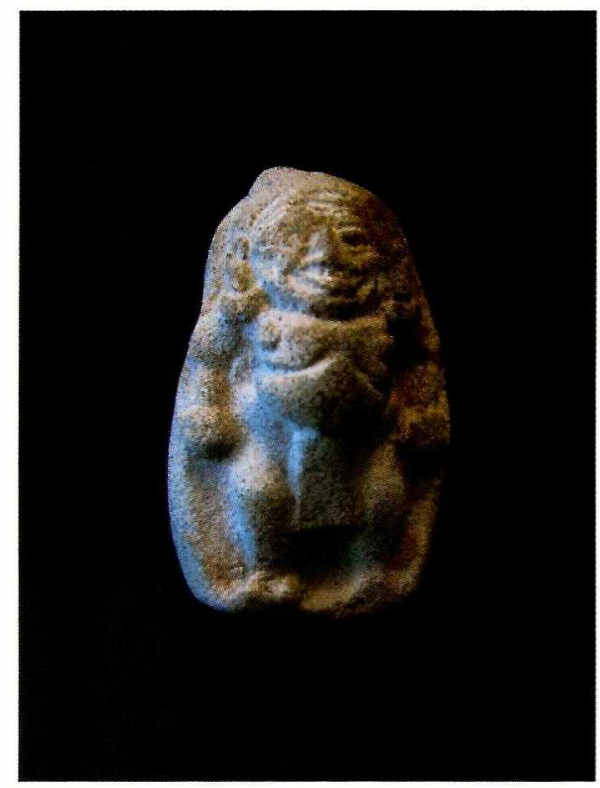

Figura 7. Personaje masculino con tórax en barril por probable displasia toráxico asfixiante de Jeune.

rencias a los enanos, a los seres con los pies torcidos asociados con el mundo subterráneo, ciertas labores y el cuidado de la naturaleza, y con los gigantes en lucha contra la sociedad en general.

Los duendes de la mitología germánica, que unos autores han asociado en su concepción con el consumo de la Amanita muscaria, en la medida que uno de los efectos de la intoxicación con este hongo son las micropsias (Fericgla, 1994), tendrían un equivalente en la forma de producción de los Desana, con el consumo entre ellos del vixó y el yajé. El hecho de que ni los Páez ni los Ika tengan tradición de usar plantas propiamente alucinógenas, no descarta que la visión de los estados modificados de conciencia inducidos por los ayunos, la meditación, los trasnoches, el consumo de tabaco mezclado con otras plantas, como por ejemplo con sales de origen vegetal, el ambil y el yua llamado así, respectivamente, entre los amazónicos y los arhuacos, o del consumo de hayo (coca) y las bebidas fermentadas y en la actualidad el alcohol, contribuyan a tener visiones especiales sobre el tamaño de las personas.

La representación del ser pequeño, del enano parece corresponder al símbolo de la fuerza regeneradora y de la totalidad de nuestro ser, mientras que la del gigante, menos frecuente, a las fuerzas que constriñen la vida, a la sexualidad exagerada y en general a las fuerzas desequilibrantes y peligrosas. Esta concepción de enanos y gigantes en las mitologías indígenas colombianas concuerda con la que los diferentes pueblos de otras latitudes tuvieron sobre elfos, gnomos, enanos, pitufos y hadas por un lado y gigantes y cíclopes por el otro.

Al concebir a los enanos con el color de la sangre, el rojo, como ocurre en las culturas Barrí y Yukpa de la Serranía de Perijá, los Desana de la cuenca amazónica y los Sicuani de la cuenca orinoquence, su vínculo con la fertilidad, con la vida es evidente. Los gigantes son claramente pensados como seres peligrosos en las mitologías de los Desana y los Ika.

\section{Conclusión}

Los enanos asociados en las mitologías de los pueblos indígenas- Ika, Bari, Yukpa, Desana, Páez, Embera y Sicuani- con el poder fálico representado por los bastones, a la sexualidad y a la vitalidad por su capacidad de generar vida y el color rojo, al ser concebidos como seres tutelares de las rique- 
zas de la madre tierra y dueños de los animales, son respetados y objetos de ofrendas. Los gigantes asociados con el riesgo vital para los recursos de la madre tierra son percibidos como seres peligrosos para la sociedad.

El estudio de estas concepciones mitológicas indígenas ayuda a explicar las frecuentes representaciones de enanos en el arte prehispánico de la cultura Tumaco-La Tolita, y la escasísima de gigantes.

\section{Lecturas recomendadas referidas}

- Arias S, Mota M, Pinto-Cisternas. Irapa type spondyloepiphyso-metaphyseal osteochondrodysplasia. New type of dwarfism with short spine and metatarsals. Nouv Presse Med. 1976 Feb 7;5(6):319-23.

- Arias S, Etiología múltiple del enanismo entre los indios Yukpa (Irapa) de la Sierra de Perijá. Boletín indigenista venezolano. 1976; 17(13) 49-70.

- Coon CS. Adaptaciones raciales. Un estudio de los orígenes, naturaleza y significado de las variaciones raciales en los humanos. Barcelona: Labor Universitaria; 1984.

- Cortés H. Cartas de la Conquista de México: carta segunda. Madrid: Biblioteca de la Historia Sarpe; 1985.
- Fericgla, JM. El hongo y la génesis de las culturas. Barcelona: Los Libros de la Liebre de Marzo; 1994.

- Guaman Poma de Ayala F. Nueva crónica y buen gobierno. Crónicas de América. Historia 16, Madrid : Siglo XXI Editores; 1987.

- Llano Vargas, H. Los chamanes jaguares de San Agustín. Génesis de un pensamiento mitopoético. Santafé de Bogotá: Cuatro y Compañía, 1995.

- Puerta Restrepo M. Tierradentro: territorio mágico. Bogotá: Editorial Carrera 7; 2001.

- $\quad$ Reichel-Dolmatoff, G. Desana: simbolismo de los indios Tukano del Vaupés. Bogotá: Procultura; 1986.

- RodríguezA. Entrevista concedida al autor el 30 de enero de 2007.

- Sotomayor Tribín H. Enfermedades en el arte prehispánico colombiano. Boletín del Museo del Oro. 1990; 29: 63-73.

- Sotomayor Tribín H. Arqueomedicina de Colombia prehispánica. 1a ed. Bogotá: Cafam. Comisión del V Centenario; 1992.

- Sotomayor Tribín H. Arqueomedicina de Colombia prehispánica. 2a ed. Santafé de Bogotá: Universidad Militar Nueva Granada; 1999.

- Vasco, LG. Jaibanás los verdaderos hombres. Bogotá: Biblioteca Banco Popular; 1985.

- Viku, A. Entrevista concedida al autor el día 21 de enero de 2007.

- Vitoria Petit A. Episodios en la naturaleza limítrofe. Cali: Panamericana; 2002. 